\title{
Desafios atuais da Ciência da Informação no Brasil ${ }^{1}$
}

\author{
Maria Yêda Falcão Soares de Filgueiras Gomes
}

\author{
Instituto de Ciência da Informação \\ Programa de Pós-Graduação em Ciência da \\ Informação-POSICI da Universidade Federal da \\ Bahia. Professora Permanente
}

Aborda a Ciência da Informação através das articulações entre os seus sistemas de pós-graduação e de pesquisa e a formação profissional a nível de graduação. Examina como essa área vem reagindo, no Brasil, aos desafios para sua expansão, consolidação e maior visibilidade. Busca, assim, entender como este campo vem respondendo às demandas de diversas naturezas que a sociedade Ihe coloca, no que diz respeito à formação de docentes, de pesquisadores, de gestores e de técnicos altamente capacitados. Com essa perspectiva, o trabalho foi estruturado em 4 partes: na primeira, apresentamos $o$ perfil atual da pós-graduação em Ciência da Informação no Brasil, dentro do Sistema Nacional de Pós-Graduação; na segunda, tratamos da pesquisa e mostramos suas tendências atuais; na terceira, traçamos um panorama geral da graduação e discutimos sua articulação com a pós-graduação e a pesquisa. Na quarta parte, tecemos algumas considerações sobre a complexidade das articulações entre essas instâncias.

Palavras-chave: Articulação Ensino de Graduação; PósGraduação e Pesquisa em Ciência da Informação; Desafios atuais.

\section{Present Challenges of the Information Science in Brazil}

This article examines the field of information science through the articulations among its graduate programs, research sector, and the professional development at the undergraduate level. It analyses how information science has faced the present challenges in Brazil to expand and

\footnotetext{
1 Projeto em desenvolvimento com Bolsa de Produtividade em Pesquisa do CNPq, processo
} n०312545/2006-1. 
consolidate itself as a field of study and gain more visibility. Therefore, it analyses how this field has been responding to the various demands made by the society in general, regarding the professional development of teachers, researchers, managers, and highly specialized technicians. From this perspective, this work was divided into four parts: in the first one, we construct the present profile of the graduate courses in information science in Brazil within the National System of Graduate Studies (Sistema Nacional de Pós-Graduação); in the second part, we focus on research and its present tendencies; in the third one, we draw a general panorama of the undergraduate courses and analyse how they are articulated with the graduate courses and the research field. In the fourth part, we comment on the complexity of the articulations within these areas.

Keywords: Articulation Undergraduate Studies; Graduate Studies and Research in Information Science; Present Challenges.

Recebido em 15.12.2008 Aceito em 04.12.2009

\section{Introdução}

Área nova, ainda em processo de consolidação, a Ciência da Informação emerge enquanto campo do conhecimento em resposta aos desafios colocados pelo desenvolvimento técnico-científico do século $X X$, principalmente em sua segunda metade. Embora seja a expressão de novas lógicas sócio-econômicas e culturais e se valha de novos e diferentes meios técnicos, o campo da Biblioteconomia e da Documentação é aquele a que, acadêmica e institucionalmente, este novo campo em formação se articula.

Este trabalho busca abordar a área de Ciência da Informação através das articulações entre os seus sistemas de pós-graduação e de pesquisa e a formação profissional a nível de graduação. Ao fazê-lo, ele examina como a Ciência da Informação vem reagindo, no Brasil, aos desafios para sua expansão, consolidação e maior visibilidade; em outras palavras, ele busca entender como este campo vem respondendo às demandas de diversas naturezas que a sociedade lhe coloca, no que diz respeito à formação de docentes, de pesquisadores, de gestores e de técnicos altamente capacitados.

Que avanços, impasses, desafios e perspectivas podemos detectar para (re)pensarmos as políticas institucionais - para a área e para os programas que a compõem? Como vem ocorrendo a interseção entre o que se pesquisa na área, a maneira como se estrutura a pós-graduação e a formação profissional que se oferece na graduação? 
Encontrar respostas para essas questões não é tarefa fácil. Tentar fazê-lo nos ajudará, entretanto, a discutir as principais variáveis que interferem no processo de articulação entre a formação propiciada pela pós-graduação e a formação profissional que a graduação deve assegurar. Com essa perspectiva, este artigo está estruturado em 4 partes: na primeira, apresentamos o perfil atual da pós-graduação em Ciência da Informação dentro do Sistema Nacional de Pós-Graduação; na segunda, tratamos da pesquisa e mostramos suas tendências atuais; na terceira parte, traçamos um panorama geral da graduação na área e discutimos sua articulação com a pós-graduação e a pesquisa; e, finalmente, na quarta parte, tecemos algumas considerações sobre a complexidade das articulações entre essas instâncias. Ao explorar os avanços e dificuldades que a área enfrenta, e a complexidade dessas articulações, pretendemos contribuir para a definição de políticas que a fortaleçam como um todo.

\section{Perfil da pós-graduação em Ciência da Informação no Brasil}

A Ciência da Informação é introduzida no Brasil com essa denominação como um curso de mestrado, criado em 1970 pelas bibliotecárias que dirigiam o Instituto Brasileiro de Bibliografia e Documentação (IBBD), para dar suporte às atividades que o órgão desempenhava no campo da informação científica e tecnológica, e para manter a comunidade profissional em sintonia com o desenvolvimento internacional da área ${ }^{2}$. Até meados dos anos 1990, o Instituto Brasileiro de Informação em Ciência e Tecnologia (IBICT), órgão que em 1976 sucedeu ao IBBD, foi o "único lastro institucional da Ciência da Informação no Brasil, pois só em seu curso de mestrado e nas práticas bibliográficas e documentais que o IBICT desenvolvia, a disciplina encontrava a sua materialidade" (ODDONE, 2004).

Ainda na década de 1970, em consonância com o esforço de instituir um Sistema Nacional de Pós-Graduação (SNPG), cinco cursos de mestrado em Biblioteconomia foram criados: na Universidade de São Paulo (USP), em 1972; na Universidade Federal de Minas Gerais (UFMG), em 1976; na Pontifícia Universidade Católica da Campinas (PUCCAMP), em 1977; na Universidade de Brasília (UnB) e na Universidade Federal da Paraíba (UFPb), em 1978. Os cursos de doutorado só surgiriam duas décadas depois: em 1992 foram criados os doutorados em Ciência da Informação do IBICT e da UnB; e em 1997, o da UFMG ${ }^{3}$. Foram criados também três novos mestrados na área: na Universidade Federal da Bahia (UFBA), em 1998; na Universidade Federal de Santa Catarina (UFSC), em 2003; e na Universidade Estadual de São Paulo (UNESP), em 2004. Em 2006, a UNESP implantou o seu doutorado, e o novo Programa de Pós-Graduação

2 Curso pioneiro não só no país, mas também na América Latina, tendo sido implantado com mandato acadêmico da Universidade Federal do Rio de Janeiro.

${ }^{3}$ Durante todo esse período (1970-1990), ao contrário do IBICT, todas as escolas e faculdades que mantinham mestrados em Biblioteconomia estavam organizadas em torno de cursos de graduação em Biblioteconomia e Documentação. 
em Ciência da Informação (mestrado e doutorado) da Escola de Comunicação e Artes (ECA) da USP começou a funcionar de modo autônomo, como um desdobramento de uma área de concentração do Programa de Pós-Graduação em Comunicação ${ }^{4}$. Ao longo de suas trajetórias, todos sofreram reformulações em suas áreas de concentração, linhas de pesquisa e grade curricular, notando-se inclusive a progressiva e reveladora alteração em suas denominações, de "Biblioteconomia e Documentação" para "Ciência da Informação".

De um modo geral, pode-se afirmar que esses programas, inicialmente, vieram atender às necessidades relativas à preparação de agentes de informação tecnológica, de analistas de sistemas de informação, de animadores culturais, de gerentes de recursos informacionais e de administradores de redes e sistemas de informação, além, naturalmente, da formação de docentes para o ensino superior.

Se, de um lado, a criação do pioneiro Mestrado em Ciência da Informação do IBBD o torna contemporâneo das primeiras iniciativas de implantação de um Sistema Nacional de Pós-Graduação no país, de outro, constata-se um crescimento lento do número de programas nessa área, em proporções bem menores que em outras áreas; o que, além de contribuir para a sua pouca visibilidade no âmbito do SNPG, coloca algumas questões acerca desse "descompasso". Assim, de 1976, ano de início do processo de avaliação dos cursos de pós-graduação pela Coordenação de Aperfeiçoamento de Pessoal de Nível Superior (CAPES), ao ano de 2004, houve um crescimento considerável no número total de cursos de mestrado e doutorado no país: o número de mestrados saltou de 490, em 1976, para 1959, em 2004; e o de doutorados passa de 183 para 1034, nesse mesmo período. Ao dirigirmos nosso foco para o período de 1996 a 2004 e para a grande área das Ciências Sociais Aplicadas, na qual a Ciência da Informação se insere, constata-se que o número de cursos de mestrado passou de 92 para 236, e o de doutorado de 27 para 82, crescimento este considerado expressivo no âmbito do SNPG (BRASIL, 2005, p. 31-37). De 2004 a 2008, podemos observar a continuação do crescimento do número de cursos de mestrado e doutorado que, nessa grande área, passou de 236 para 297, e de 82 para 112, respectivamente. Contudo, a participação da Ciência da Informação nesse quadro geral de crescimento de sua grande área foi muito pequena, passando de 5 programas, em 1996, para 7 programas em 2003. Mantém esse mesmo número de programas em 2004 e 2005; em 2006 cresce para oito 8, e em 2008 para 10 programas. Se compararmos esses dados com os da área de Comunicação, também incluída na mesma grande área, constatamos que ela cresce mais rapidamente no mesmo período, saltando de 8 programas em 1996 para 24 em 2006, e para 35 em 2008 (BRASIL, 2008c). Observa-se assim que o crescimento da área de Ciência da Informação foi pouco expressivo, não apenas no contexto da grande área

\footnotetext{
4 Em 1972, iniciou-se o mestrado, e até 1990 respondia pela área de concentração "Biblioteconomia" no Programa de Pós-Graduação em Ciência da Comunicação. Em 1980, passou a oferecer o doutorado, tendo sido o primeiro e único durante doze anos. A partir de 1991, consolida-se a área de concentração em "Ciência da Informação e Documentação".
} 
das Ciências Sociais Aplicadas, mas em todo o Sistema Nacional de PósGraduação.

No que diz respeito ao número de titulados em Ciência da Informação, constatou-se na última avaliação da Capes, relativa ao triênio 2004-2006, que houve uma evolução, principalmente no número de doutores formados: neste triênio, os programas titularam um total de 288 mestres e 61 doutores, ocorrendo assim um expressivo aumento quantitativo, na medida em que, no triênio anterior (2001-2003), os programas haviam formado 228 mestres e 43 doutores, e no triênio 19982000, apenas 206 mestres e 30 doutores.

Embora possamos observar que dobrou o número de doutores titulados entre 2000 e 2006, constatou-se, ainda na avaliação trienal 2004-2006, a necessidade de uma formação intensiva de doutores na área, tanto para o fortalecimento da pós-graduação e da pesquisa, quanto para a dinamização da graduação. Nessa última avaliação, ocorreu também o descredenciamento de um dos seus programas 5 .

Atualmente, a pós-graduação em Ciência da Informação engloba apenas 10 programas, dos quais cinco só oferecem cursos de mestrado (UFBA, UFPb, UEL, UFSC e UFF), e cinco oferecem cursos de mestrado e doutorado (USP, UNESP, UFMG, UFRJ e UnB). A Universidade Federal do Rio Grande do Sul oferece uma área de concentração em Ciência da Informação, no âmbito do seu Programa de Pós-Graduação em Comunicação, e a Universidade Estadual de Londrina (UEL) oferece um mestrado profissional em Gestão da Informação, o primeiro desta categoria na área, que foi credenciado em 2007, embora só tenha começado a funcionar no segundo semestre de 2008. Cabe ainda destacar que o PPGCI do IBICT/UFF finalizou seu convênio em 2008, mas funcionará em conjunto até 2010, quando deverão ser concluídas as defesas de mestrado e doutorado ainda pendentes. Nesse mesmo ano de 2008, a UFF apresentou proposta para credenciamento de um Mestrado em Ciência da Informação, tendo como área de concentração "As Dimensões Contemporâneas da Informação e do Conhecimento". O IBICT, por sua vez, apresentou proposta para voltar a associar-se à UFRJ, agora com a Faculdade de Administração e Ciências Contábeis - FACC. Além desses programas, há outras iniciativas de pós-graduação que contemplam estudos sobre Informação, embora não se constituam como programas e/ou cursos especificamente da área da Ciência da Informação. Na Universidade Federal do Paraná, foi criado em 2008 o Mestrado em Ciência, Gestão e Tecnologia da Informação, credenciado na área Multidisciplinar. Outro curso credenciado pela Capes, também em 2008, na mesma área Multidisciplinar, foi o Programa de Pós-Graduação em Informação e Comunicação em Saúde, promovido pelo Instituto de Comunicação e Informação Científica e Tecnológica em Saúde - ICICT, da Fundação Oswaldo Cruz - FIOCRUZ, em níveis de mestrado e doutorado.

\footnotetext{
5 Na última avaliação trienal da Capes, relativa ao triênio 2004-2006, o Curso de Mestrado em Ciência da Informação da PUCCAMP foi descredenciado.
} 
Embora com a aprovação, em 2008, de novos cursos de mestrado na área, observa-se um desequilíbrio regional em sua distribuição, com a concentração de cinco deles na região Sudeste, seguidos por 2 na região Sul, 2 na região Nordeste, um na região Centro-Oeste, e nenhum na região Norte. Ampliar ainda mais o número de programas de pósgraduação da área, distribuindo-os de forma mais equilibrada pelas regiões do país, é um outro desafio que se coloca para a área, e isso deverá ser enfrentado o quanto antes.

No que diz respeito à seleção de alunos para os programas de pósgraduação da área, a prioridade deve recair naqueles candidatos que aliam mérito à perspectiva de inserção em atividades acadêmicas, o que reforçará a formação de quadros para o ensino superior em Ciência da Informação. Sugere-se também a criação de equipes permanentes de pesquisa, integrando docentes, alunos de pós-graduação e de graduação.

\section{A pesquisa}

Não existem mais dúvidas sobre os estreitos vínculos entre o desenvolvimento da pesquisa em biblioteconomia e ciência da informação no Brasil e o advento da pós-graduação strictu senso nessas áreas, implantada, como vimos, a partir da década de 1970 - relação esta que, de resto, também pode ser feita para muitas outras (senão para todas) áreas do conhecimento.

Apesar da criação de novos mestrados e de mais um doutorado em ciência da informação no período de 1998 a 2008, a participação dessa área no total da ação de fomento do Conselho Nacional de Desenvolvimento Científico e Tecnológico (CNPq) nesse período foi muito pequena. As dez áreas com maior percentual de participação foram a da Física, em primeiro lugar, seguida das áreas de Química, Agronomia, Medicina, Geociências, Ciência da Computação, Engenharia Elétrica, Saúde Coletiva, Bioquímica e Engenharia de Materiais e Metalúrgica. A Ciência da Informação ocupou $070^{\circ}$ lugar, com percentual de participação de apenas 0,4 em 1998 e 1999; decrescendo em 2000 e 2001 para 0,3 e estacionando em 0,2 nos anos seguintes; ou seja, caiu para a metade, o que significa muito pouco investimento realizado em bolsas e no fomento à pesquisa pelo CNPq nessa área. Cabe ressaltar que esta redução acontece no período em que se desenvolve a pós-graduação no país. Mesmo áreas que não tiveram também uma participação expressiva no total desses investimentos, a exemplo de Filosofia, no $46^{\circ}$ lugar; Comunicação, no $48^{\circ}$; Geografia, no $50^{\circ}$, e Arquitetura e Urbanismo, no $60^{\circ}$, embora com percentuais de participação modestos no sistema nacional de fomento à pesquisa, decresceram pouco, no referido período, se comparadas à Ciência da Informação (BRASIL, 2008b).

Quanto aos grupos de pesquisa registrados no Diretório dos Grupos de Pesquisa do CNPq, identificamos o total de 45 grupos na área de Ciência da Informação. Os assuntos mais pesquisados relacionam-se à representação e organização da informação e do conhecimento; à teoria, epistemologia e interdisciplinaridade da ciência da informação; às 
tecnologias da informação; à economia e política da informação, e à informação e cultura, memória e sociedade; envolvendo docentes, alunos de pós-graduação e graduação. Há também grupos cadastrados como pertencendo à área da Ciência da Informação, mas que, na prática, estão mais voltados para o Desenho Industrial, a Administração, a Economia, a Comunicação e o Serviço Social. Se incluirmos essas áreas conexas, o número sobe para 63 grupos. A notar ainda que vários desses grupos não vêm sendo atualizados há mais de doze meses, o que suscita dúvidas sobre a efetividade do seu funcionamento (BRASIL, 2008a).

$\mathrm{Em}$ pesquisa em que foram analisadas, quantitativamente, as dissertações e teses defendidas nos períodos de 1990-1999 e 2000-2002, segundo as linhas de pesquisa de nove Programas de Pós-Graduação em Ciência da Informação, Población e Noronha (2003) destacaram mudanças no enfoque central das pesquisas, com a implantação dos doutorados a partir da década de 1990. Esse enfoque deslocou-se do ambiente biblioteca para o foco da informação, ampliando para sistemas de informação, análise de produção do conhecimento, usuários da informação e processos de comunicação, contemplando os fluxos e linguagens de informação. As linhas de pesquisa foram definidas de forma que profissionais graduados, não só em biblioteconomia, mas também de diversas áreas do conhecimento, sintam-se atraídos para desenvolver pesquisas que dialoguem com a ciência da informação; ou seja, pesquisas que explorem a interdisciplinaridade nas áreas envolvidas.

Entre 2001 e 2006 ocorreram expressivas modificações no enunciado das áreas de concentração e das linhas de pesquisa dos programas de pós-graduação em Ciência da Informação, que passaram a refletir melhor o caráter interdisciplinar de seu objeto e a perseguir uma construção disciplinar do mesmo, conferindo assim maior consistência ao conhecimento produzido no interior desses programas.

De acordo com Stumpf (2008, p. 97), através de uma análise das linhas de pesquisa dos programas de pós-graduação em Ciência da Informação no país - e sendo necessário que os projetos de pesquisa dos docentes estejam vinculados à linha de pesquisa -, pode-se concluir que "as temáticas de pesquisa têm sido organizadas em torno do acesso e uso da informação, dos enfoques culturais e sociais do objeto informacional, além da gestão da informação e do conhecimento".

Um importante passo para a visibilidade, divulgação e consolidação da pesquisa na área foi dado em junho de 1989, com a criação da Associação Nacional de Pesquisa e Pós-Graduação em Ciência da Informação e Biblioteconomia (ANCIB) que, a partir de 1994, vem promovendo os Encontros Nacionais de Pesquisa em Ciência da Informação (ENANCIBs), o que a torna a principal sociedade científica da área. O conjunto dos trabalhos apresentados nesses encontros pode ser considerado representativo da produção nesses campos ao longo do tempo.

Observando-se a evolução dos Grupos de Trabalhos (GTs) da ANCIB, entre 1994 e 2006, podemos constatar o gradual "deslocamento" da área em direção a temas mais densos e mais afinados com as 
temáticas contemporâneas ligadas às tecnologias eletrônicas e à complexidade da sociedade da informação. É cada vez maior a importância das novas tecnologias da informação e comunicação nas pesquisas desenvolvidas no âmbito da Ciência da Informação, com enfoques diversos, privilegiando não apenas os fatores tecnológicos da busca e recuperação da informação, mas se direcionando também para abordagens que privilegiam o aspecto humano e as questões relacionadas à subjetividade dos usuários no processo de busca e uso da informação; conforme se pode evidenciar através do crescente volume de comunicações apresentadas nos Encontros realizados pela Associação, a partir do ano 2000.

Observa-se também um redirecionamento nos seus processos investigativos, no sentido de buscar, cada vez mais, embasamento em métodos qualitativos, o que indica uma nova sensibilidade dos pesquisadores em suas investigações (GOMES, 2007). Ao referir-se às temáticas que mais necessitam ser pesquisadas, Pinheiro (2005) destacou que as pesquisas de cunho teórico e epistemológico sobre a ciência da informação no Brasil são pouco numerosas e, na maior parte, estão concentradas no PPGCI da UFF/IBICT; o que, segundo Pinheiro (2005), "pode ser explicado por ser este o único Programa a incluir uma linha específica sobre epistemologia e interdisciplinaridade" ( $p$. 97). As interfaces com as outras áreas do conhecimento estão presentes, sobretudo com a computação, sociologia, educação, ciências cognitivas, lingüística, lógica e história da ciência. De acordo com a última avaliação da Capes, no período 2004-2006, a área amadureceu, enfatizou menos sua necessidade de afirmação de uma identidade, priorizando as pesquisas que objetivam propor soluções para os imensos problemas colocados pelo acesso à informação na contemporaneidade (CAPES, Documento de Área 2004-2006).

\section{Panorama geral da graduação}

Na sociedade da informação, as mudanças operadas pela inovação tecnológica nos setores da informática, redes de computadores e telecomunicações afetam a concepção tradicional de bibliotecas, centros de documentação e outras unidades e serviços de informação, e, conseqüentemente, introduzem a necessidade de mudanças na formação do bibliotecário, a fim de que possa desempenhar melhor suas novas funções e fazer face aos desafios inerentes à era da informação eletrônica.

Existem atualmente 46 cursos de graduação na área, com diferentes denominações, tais como Biblioteconomia; Biblioteconomia e Gestão de Unidades de Informação; Ciência da Informação; Ciência da Informação e Documentação; Administração da Informação; Arquivologia; e Gestão da Informação, dentre outras. Esses cursos concentram-se nas regiões Sudeste, com 21 deles; Sul, com 8; Nordeste, também com 8; CentroOeste, com 5; e Norte, com apenas 2 cursos $^{6}$. Alterações curriculares vêm

\footnotetext{
${ }^{6}$ Não estão incluídos nessa relação os cursos de Museologia.
} 
sendo operadas nesses cursos com base nas diretrizes aprovadas pela Câmara de Educação Superior do Conselho Nacional de Educação, em abril de 2001, buscando adequar a formação profissional às novas demandas da sociedade da informação. Essas diretrizes referem-se ao perfil dos formandos com suas competências e habilidades; aos conteúdos curriculares dos cursos; estágios e atividades complementares; à estrutura do curso; e à avaliação institucional. Nessa formação, a pesquisa é entendida como princípio educativo e sua articulação com o ensino e a extensão deverá ser garantida pelas instituições; não só pela infra-estrutura material e humana, mas sobretudo pela constituição de ambientes que envolvam alunos de graduação, pós-graduação e profissionais da área num processo de reflexão crítica e troca de experiências, permitindo a interlocução entre a universidade e a sociedade. No que diz respeito a esse perfil, essas diretrizes definem que,,..

... além de preparados para enfrentar com proficiência e criatividade os problemas de sua prática profissional, produzir e difundir conhecimentos, refletir criticamente sobre a realidade que os envolve, buscar aprimoramento contínuo e observar padrões éticos de conduta, os egressos dos referidos cursos deverão ser capazes de atuar junto a instituições e serviços que demandem intervenções de natureza e alcance variados: bibliotecas, centros de documentação ou informação, centros culturais, serviços ou redes de informação, órgãos de gestão do patrimônio cultural, etc. (BRASIL., 2001).

Desse modo, os cursos/escolas devem buscar, através de novas propostas curriculares, fundamentadas nessas diretrizes curriculares e evidenciadas através dos seus projetos político-pedagógicos, um perfil profissional de natureza mais interdisciplinar, que possa dar conta de uma realidade heterogênea, em um tempo de rápidas e profundas mudanças, com um aparato tecnológico constantemente em aperfeiçoamento e com usuários cada vez mais exigentes.

Os documentos produzidos pela Associação Brasileira de Educação em Ciência da Informação (ABECIN), no âmbito de variados foros realizados nesses últimos anos, voltados para a discussão e proposição de diretrizes para o ensino, destacam, entre outros aspectos, a importância da formação científica na graduação, a necessidade de uma integração mais orgânica entre esta e a pós-graduação, e a busca do aperfeiçoamento de seus vínculos. Enfatizam ainda a importância da pesquisa no processo de formação, seja no âmbito do ensino (ensino com pesquisa) ou no âmbito da extensão (ação com pesquisa), bem como sua importância para o crescimento profissional. Rodrigues (2004) destacou que, a partir de 2001, a ABECIN apresentou para implementação uma agenda de trabalho propositiva e pró-ativa em nível nacional, e tem cumprido esse propósito junto aos cursos de graduação das áreas de Biblioteconomia e Ciência da 
Informação. A formulação de uma política de formação para essas áreas é o corolário desse processo, que deverá se sustentar nos seguintes eixos: i) Novo perfil profissional - integrar a formação técnica à humana e ética; ii) Princípio pedagógico - ensino articulado à pesquisa; iii) Articulação graduação/pós-graduação; e iv) Avaliação - qualidade do ensino (p. 172).

A necessidade de formação pós-graduada do corpo docente que atua na graduação é destacada na Lei de Diretrizes e Bases para a Educação Nacional, ao definir que os cursos de graduação devem ter "um terço do corpo docente, pelo menos, com titulação acadêmica de mestrado ou doutorado" (BRASIL, 1996). A formação de graduação dos docentes dos cursos da área no país é, na sua maioria, na própria área, caracterizando uma endogenia que nada facilita a interdisciplinaridade e a integração de saberes para a construção do arcabouço teórico da área.

Em estudo sobre as características do perfil dos doutores titulados nos Programas de Pós-Graduação em Ciência da Informação, no período de 2000-2005, e da inserção desses egressos nas instituições brasileiras de ensino e pesquisa, Noronha et al. (2007) constataram o crescimento do envolvimento desses doutores em atividades de ensino com destaque na graduação. Dos 104 currículos analisados, verificou-se que estavam atuando no ensino, em diferentes instituições brasileiras, doutores vinculados às atividades de graduação $(78,8 \%)$, de pós-graduação $(43,3 \%)$ e de cursos de especialização $(17,3 \%)$. Do total de egressos envolvidos no ensino de graduação (82), o maior percentual provinha do programa do IBICT (33\%), seguido do da USP (27\%), UFMG (25\%) e UnB (15\%). De acordo com esses autores, os egressos desses programas estariam inseridos na vida acadêmica, integrando o corpo docente das diferentes instituições públicas ou particulares de ensino e/ou pesquisa, segundo sua vocação ou oportunidades oferecidas pelo mercado, não só em ciência da informação como também em áreas interdisciplinares.

No geral, a pesquisa se faz presente, no contexto da graduação, no momento da realização dos Trabalhos de Conclusão de Curso (TCC), em que os alunos têm a possibilidade de vivenciar uma atividade de investigação. Com relação às bolsas de iniciação científica, instrumentos privilegiados para o graduando participar de projetos de pesquisa, é fundamental destacar que, concedidas por quota ao orientador, sua elevada demanda por parte do conjunto das áreas aumenta a competitividade entre estas, reduzindo o número daquelas à disposição das áreas menos privilegiadas dentro do sistema, como é o caso da Ciência da Informação. Como decorrência, restringem-se as possibilidades de uma formação aliada à pesquisa, deixando-se igualmente de preparar, desde a graduação, o futuro candidato à pós-graduação.

Dentre as várias formas de trabalhar a articulação entre ensino e pesquisa nos cursos de graduação, a mais rica e promissora seria, sem dúvida, transformar a pesquisa em eixo ou núcleo central do curso e elemento norteador de toda a estrutura curricular. Há também a possibilidade de os docentes inserirem seus próprios temas e projetos de pesquisa nos programas das disciplinas, dando a seus alunos a oportunidade de discutir os resultados dessas pesquisas, os dados 
analisados, a metodologia utilizada, para que, a partir daí, possam propor e gerar novos temas e problemas. Destaca-se assim a importância da pesquisa como estratégia pedagógica, "que permita a união do fazer com o teorizar e o fazer, levando o aluno a observar, a refletir, a dialogar com a realidade e agir sobre ela" (RODRIGUES, 1998, p. 41).

No que diz respeito à integração graduação/pós-graduação, o Documento de Área da Capes, relativo ao triênio 2001-2003, já destacava, entre outros aspectos, que, se o objetivo de formação e titulação do corpo docente das IES, através dos programas de pósgraduação implantados a partir da década de 1970, ainda não havia sido totalmente cumprido, observava-se, no entanto, que uma percentagem cada vez maior de egressos não tinha vínculo com os cursos de graduação em Biblioteconomia e Ciência da Informação. Sobre este aspecto sugeria a...

... inseminação da graduação através da pesquisa (processo este que é sensível nas IES que mantêm a formação em níveis de graduação e pós-graduação associados, através da atuação do mesmo corpo docente), divulgando a produção naqueles cursos de graduação que não mantêm vínculo com um programa de pós-graduação. No mesmo sentido, faz-se necessário um amplo estudo dos egressos da pós-graduação, para verificar com maior precisão o acerto da opinião sobre o encerramento de uma primeira grande fase da pós-graduação em Ciência da Informação no Brasil, através da análise dos perfis profissionais dos egressos e de sua atuação profissional (BRASIL, 2008c).

Já na última avaliação, referente ao triênio 2004-2006, evidenciouse ainda a necessidade de formação intensiva de doutores na área para o fortalecimento dos cursos de graduação, pós-graduação e da pesquisa. Com os ajustes implantados na estrutura dos programas ao longo do triênio 2004-2006, objetivando melhorar a delimitação de suas linhas de pesquisa, o escopo da área de concentração ou a estrutura curricular, podemos observar que a pós-graduação está em processo de consolidação. Em conseqüência dessas mudanças, constata-se, cada vez mais, a inserção das atividades de pesquisa, publicações e orientações, no campo interdisciplinar da ciência da informação. No que diz respeito à produção de livros e coletâneas, nos dois últimos triênios (2001-2003 e 2004-2006), destacou-se que essa produção foi muito positiva, pois forneceu "uma biblioteca básica para o ensino de graduação e bibliografia para iniciantes na pós-graduação". Por outro lado, considerou-se que ainda há espaços para a produção de manuais didáticos, de imensa valia para inseminar o ensino de graduação, além da ampliação da produção de monografias (BRASIL, 2008c).

A utilização da monitoria de pós-graduação pode constituir-se num eficiente mecanismo de articulação com a graduação, desde que haja uma orientação dos professores nesse sentido em seus programas de ensino e pesquisa. 


\section{Considerações finais}

A implantação da pós-graduação em Ciência da Informação no Brasil é contemporânea da própria constituição do sistema de pós-graduação no país. Contudo, nos anos 1980 ela parece "perder impulso", e somente na década de 90 , com a criação dos doutorados e, mais recentemente, com a criação de outros mestrados, é que apresenta sinais de recuperação de seu dinamismo inicial. Durante todo esse percurso, a área indubitavelmente cresceu e se fortaleceu, embora de forma lenta, constatando-se uma expansão da pesquisa e uma maior consistência epistemológica, com o conseqüente aumento de atividades (publicações, orientações) resultante desse esforço.

De uma maneira geral, todo o sistema de pós-graduação e pesquisa no Brasil vem sofrendo o impacto de profundas modificações que apontam para uma competitividade cada vez maior, um rigor crescente nos processos de avaliação dos programas e dos docentes/pesquisadores, e uma ênfase nos aspectos quantitativos da produção acadêmica. Lemos (2005) chama a atenção para as distorções resultantes da ênfase nos indicadores quantitativos nos processos de avaliação de desempenho acadêmico, os quais valorizam, cada vez mais, o volume de trabalhos publicados, em detrimento da qualidade do que é produzido. Dentre as diretrizes do Plano Nacional de Pós-Graduação (PNPG) para o período 2005-2010, destaca-se a ousada expectativa de se dobrar o número de doutores titulados no período de vigência do plano. Para a grande área das Ciências Sociais Aplicadas, na qual se insere a Ciência da Informação, as metas estabelecidas prevêem, para 2010, a titulação de mais 2.141 mestres e 583 doutores, o que corresponde a um acréscimo de $42 \%$ e 79\%, respectivamente, em relação a 2003 (BRASIL, 2005, p. 80).

$\mathrm{Se}$, por um lado, constatam-se efetivamente avanços no modo como a área vem respondendo às exigências dos sistemas de avaliação da pósgraduação e da pesquisa no Brasil, por outro lado, evidencia-se também uma série de desafios que ela precisa enfrentar, particularmente no que diz respeito à sua situação, papel e atuação no âmbito do Sistema Nacional de Pós-Graduação e da sociedade em geral. A expansão do conjunto desse sistema não vem sendo acompanhada pela expansão dos recursos orçamentários para o mesmo, o que, acrescido do rigor na avaliação continuada realizada pela Capes, contribui para a competitividade do sistema como um todo. Claro que esse quadro geral afeta o conjunto das áreas, porém em graus diferenciados, com nítida desvantagem para áreas novas e não consolidadas, como a ciência da informação, que se vêem obrigadas a responder a exigências cada vez mais rigorosas, imprimindo um ritmo veloz ao processo já naturalmente complexo que caracteriza a constituição e consolidação de uma área.

No plano da pesquisa, mudam rapidamente as modalidades para o seu financiamento, com diversificação de fontes e de mecanismos para captá-las (como os editais temáticos, por exemplo), impondo práticas novas e de incorporação nem sempre simples para as áreas menos "estabelecidas" ou menos "agressivas". Complexificando este quadro, há 
que se mencionar que não necessariamente existe confluência entre as políticas das agências de regulação e apoio à pós-graduação (como a Capes) e aquelas voltadas para a pesquisa (como o CNPq e as FAPS estaduais). Observa-se, por exemplo, uma desigualdade muito grande nos investimentos realizados em bolsas e no fomento à pesquisa, segundo as grandes áreas do conhecimento. No caso do CNPq, podemos constatar que, no período de 1998 a 2007, esses investimentos beneficiaram, em grande parte, as Ciências da Vida e as Ciências da Natureza, que obtiveram um percentual de participação crescente, variando de $38 \%$ a $43 \%$ e de $39 \%$ a $40 \%$, respectivamente. Já as Humanidades apresentaram um percentual participativo decrescente, com variação de 23\% em 1998, para 17\% em 2007 (BRASIL, 2008b).

González de Gómez (2004), em artigo sobre a pesquisa em ciência da informação, ao referir-se à avaliação e ao estabelecimento dos critérios de excelência, assinala que deveria haver maior integração entre as agências de fomento - Capes e CNPq -; tanto em sua definição do que seria a "excelência", quanto nos seus procedimentos avaliativos, considerando-se que tarefas que não são sempre devidamente reconhecidas como parte da produção científica podem ser condições imprescindíveis à saúde e vigor do tecido epistêmico de uma sociedade. Sobre esses aspectos, cabe ainda citar Gomes (2008), que, ao abordar o tema Avaliação da Pesquisa no âmbito do planejamento urbano e regional, lembra que existe uma diferença fundamental entre aqueles que representam suas áreas no $\mathrm{CNPq}$ e na Capes. Na Capes, o representante de área tem interlocutores na base do sistema - no caso, o conjunto de coordenadores de programas de pós-graduação - e no topo do sistema no caso, o Comitê Técnico Científico, através do qual se consegue alguma participação nas decisões relativas à formatação das políticas e à maneira como elas são aplicadas. Já no $\mathrm{CNPq}$, isso não acontece. "Não temos canais de comunicação com as nossas 'bases' - na realidade, qualquer pessoa com título de doutor pode se apresentar ao balcão do $\mathrm{CNPq}$ - o que transforma nossos 'representados' em uma massa difusa, impossibilitando qualquer tipo de interlocução", afirma o referido autor. Além disto, chama ainda a atenção para o fato de não existir, no topo do sistema, nenhum canal formal ou mesmo informal que acene a possibilidade de participação na definição das políticas e das regras de sua operacionalização. Ou seja,...

... o papel de um membro do comitê assessor do CNPq acaba sendo o de implementar políticas de cuja formulação ele não participou, segundo regras que ele não definiu e voltadas para um público com quem ele não tem nenhuma possibilidade efetiva de interação (GOMES, 2008).

No que diz respeito à articulação pós-graduação/graduação, não restam dúvidas sobre o longo percurso ainda a realizar. Dentre os desafios que se colocam, destacamos a necessidade de se ampliar o número de programas de pós-graduação, estabelecendo-se um melhor equilíbrio regional na sua distribuição, visando o desenvolvimento da própria pós- 
graduação e da pesquisa, e a dinamização do ensino de graduação, através da formação pós-graduada de seu corpo docente e de mudanças na própria concepção do ensino, de modo a aproximar mais reprodução e produção do conhecimento. Galindo e Azevedo Netto (2008), ao se referirem ao processo de concentração regional dos programas de pósgraduação, chamam a atenção para o fato de que a assimetria da distribuição regional é apontada por diversos autores como um dos pontos de vulnerabilidade do sistema de pós-graduação no Brasil. No que diz respeito especificamente ao processo de concentração da Pós-Graduação em Ciência da Informação no Sudeste, observa-se como conseqüência desse processo "o agravamento da carência de mestres e doutores em CI nas regiões Norte e Nordeste e a falta de motivação por parte dos egressos da área da CI em relação à pós-graduação stricto sensu". Além disto, esses autores consideram necessário "que regiões menos atendidas pelo sistema de pós-graduação sejam tratadas com políticas especiais de apoio, suporte e fomento em benefício do desenvolvimento equilibrado da área de Ciência da Informação" (GALINDO e AZEVEDO NETTO, 2008).

Todos esses aspectos das políticas e estruturas de gestão institucional precisam ser repensados e requerem uma análise mais criteriosa por parte dos programas, da associação científica que os representa e dos pesquisadores, bem como, naturalmente, das próprias agências de fomento.

\section{Referências}

BRASIL. Conselho Nacional de Desenvolvimento Científico e Tecnológico (CNPQ). Diretório de Grupos de Pesquisa. 2008a. Disponível em: $<$ http://dgp.cnpq.br>. Acesso em: 10 dez. 2008.

BRASIL. Conselho Nacional de Desenvolvimento Científico e Tecnológico (CNPQ). Estatísticas e indicadores do fomento. 2008b. Disponível em: <http://www.cnpq.br;estatisticas;indicadores.htm>. Acesso em: $10 \mathrm{dez} .2008$.

BRASIL. Coordenação de Aperfeiçoamento de Pessoal de Nível Superior (CAPES). Documento de Área 2004-2006: Ciências Sociais Aplicadas I (Comunicação, Ciência da Informação e Museologia). 2008c. Disponível em: <http://www.Capes.gov.br/avaliação/documentos >. Acesso em: 10 dez. 2008.

BRASIL. Conselho Nacional de Educação. Diretrizes Curriculares. Brasília, 2001. Disponível em: <http://abecin.org.br/Diretrizes.htm>. Acesso em: 24 abr. 2008.

BRASIL. Leis, decretos, etc. 1996. Disponível em: $<$ http://portal.mec.gov.br/index.php>. Acesso em: 12 maio 2008.

BRASIL. Ministério de Educação. Plano Nacional de Pós-Graduação - PNPG 2005-2010. Brasília: MEC, 2005. 262p.

GALINDO, M.; AZEVEDO NETTO, C. X. Distribuição dos recursos de formação em Pós-graduação. O caso da Ciência da Informação no Nordeste do Brasil. In: ENCONTRO NACIONAL DE PESQUISA EM CIÊNCIA 
DA INFORMAÇÃO, 9., São Paulo, 2008. Anais... São Paulo: USP; ANCIB, 2008. CD-ROM.

GOMES, M. A. A. F. O sistema de fomento à pesquisa no Brasil e os estudos urbanos e regionais: subsídios para uma política de área. In: SEMINÁRIO DE AVALIAÇÃO DO ENSINO E DA PESQUISA EM ESTUDOS URBANOS E REGIONAIS, 4., Belém, 2008. Mesa Redonda Avaliação da Pesquisa e Perspectivas em Planejamento Urbano e Regional. Anais... Belém: ANPUR, 2008.

GOMES, M. Y. F. S. F. Perspectivas da Ciência da Informação no Brasil: um estudo através das comunicações apresentadas no VI ENANCIB. In: ENCONTRO NACIONAL DE PESQUISA EM CIÊNCIA DA INFORMAÇÃO, 8., Salvador, 2007. Anais... Salvador: UFBA; ANCIB, 2007. CD-ROM.

GONZÁLEZ DE GÓMEZ, M. N. A pesquisa em Ciência da Informação: da epistemologia institucional à política do conhecimento. In: WORKSHOP EM CIÊNCIA DA INFORMAÇÃO, Niterói, 2004. Anais... Niterói: UFF; ANCIB, 2004. p.113-125.

LEMOS, A. A. B. Publicar e perecer. Ciência da Informação, Brasília, v. 34, n. 2, p. 7-8, maio/ago. 2005.

NORONHA, D. P. et al. Doutores egressos dos programas de pósgraduação em Ciência da Informação: temática das teses defendidas e atual vínculo docente. In: ENCONTRO NACIONAL DE PESQUISA EM CIÊNCIA DA INFORMAÇÃO, 8., Salvador, 2007. Anais... Salvador: UFBA; ANCIB, 2007. CD-ROM.

ODDONE, N. Lydia de Queiroz Sambaquy e a Ciência da Informação. In: ENCONTRO NACIONAL DE PESQUISA EM CIÊNCIA DA INFORMAÇÃO, 6., Florianópolis, 2005. Anais... Florianópolis: UFSC; ANCIB, 2005. CD-ROM.

PINHEIRO, L. V. R. Processo Evolutivo e Tendências Contemporâneas da Ciência da Informação. Informação \& Sociedade: Estudos, João Pessoa, v.15, n.1, p.13-48, 2005.

POBLACIÓN, D. A.; NORONHA, D. P. Rumos da comunidade brasileira de pesquisadores em Ciência da Informação: desafios do século XXI. In: ENCONTRO NACIONAL DE PESQUISA EM CIÊNCIA DA INFORMAÇÃO, 5., Belo Horizonte, 2003. Anais... Belo Horizonte: UFMB; ANCIB, 2003. CDROM.

RODRIGUES, M. E. F. A pesquisa como estratégia pedagógica para a competência profissional. In: ENCUENTROS DE DIRECTORES, 3 Y DE DOCENTES DE LAS ESCUELAS DE BIBLIOTECOLOGIA DEL MERCOSUR, 2., Santiago de Chile, 1998. Anais. Formación de Recursos Humanos em el Área de la Información en el MERCOSUR. Santiago de Chile: Universidad Tecnologica Metropolitana/Escuela de Bibliotecología, 1999. p. 41-44.

RODRIGUES, M. E. F. Posibilidades de articulação entre o ensino e a pesquisa: proposições da ABECIN. In: WORKSHOP EM CIÊNCIA DA 
INFORMAÇÃO: POLÍTICAS E ESTRATÉGIAS DE PESQUISA E ENSINO DE PÓS-GRADUAÇÃO. Anais... Niterói: UFF;ANCIB, 2004. p. 159-173.

STUMPF, I. R. Programas de Pós-Graduação em Ciência da Informação no Brasil: linhas de pesquisa, avaliação e perspectivas. In: COLÓQUIO MEDIAÇÕES E USOS DE SABERES E INFORMAÇÃO: UM DIÁLOGO FRANÇA-BRASIL, 1., Rio de Janeiro, 2008. Anais...Rio de Janeiro: ICICT/FIOCRUZ, 2008. p. 82-98. 